\title{
Are All Dentiform Teeth with Simulated Caries the Same? A Six-Year Retrospective Study in Preclinical Operative Dentistry
}

\author{
Alex J. Delgado, DDS, MS; Ricardo Walter, DDS, MS; Linda S. Behar-Horenstein, PhD; \\ Lee W. Boushell, DMD, MS
}

Abstract: Dentiform teeth with simulated caries (DTSC), frequently used in preclinical courses, should show no variability in the amount of simulated caries from tooth to tooth. However, the level of caries variability among DTSC is currently unknown. The aim of this study was to assess the variation in simulated caries levels in one group of DTSC and determine whether variation among DTSC impacted the preclinical performance of dental students. In the study, 80 commercially available mandibular first molar DTSC with simulated mesio-occluso-distal caries were sectioned in coronal $(n=40)$ and sagittal $(n=40)$ planes where the caries depth/width was greatest. Section images were analyzed for variation in levels of simulated caries using image-processing software. Three years of practical performance data using DTSC were compared with three years of practical performance data using dentiform teeth without simulated caries, for a total of six years (students' performance on two exams, Practical 1 and Practical 2). The results showed that $70 \%$ of the coronally sectioned teeth had manufacturing defects that resulted in caries overextension at the dentino-enamel junctions (DEJs). Overextensions were found at the DEJ in $41.3 \%$ of the sagittally sectioned teeth. There was a statistically significant decrease in Practical 1 performance of the students who used DTSC as compared with students who used teeth without simulated caries $(\mathrm{p}=0.0001)$; there was no statistically significant difference on Practical 2 performance. Of the DTSC evaluated in this study, 56.6\% contained manufacturing defects, and more than $80 \%$ were found to have excessive caries variation. Prediction of which DTSC will have caries overextension is not possible. Students preparing DTSC that contain caries overextension are therefore at increased risk of receiving undeserved negative summative assessment on practical examinations.

Dr. Delgado is Clinical Assistant Professor, Department of Restorative Dental Science, Division of Operative Dentistry, College of Dentistry, University of Florida; Dr. Walter is Clinical Associate Professor and DDS3 Group Director, Department of Operative Dentistry, School of Dentistry, University of North Carolina at Chapel Hill; Dr. Behar-Horenstein is Distinguished Teaching Scholar and Professor, School of Human Development and Organizational Studies in Education and Affiliate Professor, Department of Community Dentistry and Behavioral Science, College of Dental Education, University of Florida; and Dr. Boushell is Associate Professor, Program Director of Graduate Operative Dentistry, Director of Introduction to Graduate Operative Dentistry, and Director of Conservative Operative Dentistry, Department of Operative Dentistry, School of Dentistry, University of North Carolina at Chapel Hill. Direct correspondence to Dr. Alex J. Delgado, Department of Restorative Dental Sciences, College of Dentistry, University of Florida, 1395 Center Drive, P.O. Box 100415, Gainesville, FL 32610; adelgado@dental.ufl.edu.

Keywords: dental education, operative dentistry, dental caries, clinical skills, dentiform teeth

Submitted for publication 3/3/15; accepted 4/22/15

$\mathrm{D}$ ental students at the University of North Carolina at Chapel Hill (UNC) School of Dentistry, as in many other dental schools, learn about dental caries onset and activity very early in their professional training. As part of this process, students learn that dental caries progression is influenced by the structural morphology of the enamel, dentino-enamel junction (DEJ), and dentin. ${ }^{1}$ Dental students learn the essential role of dentin in the support of the enamel and how disease extension in the interface (the DEJ) leaves the enamel "unsupported" and therefore unable to withstand occlusal forces over time. Corrective operative procedures are designed based on the location and biomechanical properties of these structures.

The principles that support the development of psychomotor skills required to accomplish diseased tissue removal and tooth restoration are taught preclinically using dentiforms that contain plastic teeth. Assessment of student ability to apply these principles, though essential, may have limited ability to predict how well subsequent clinical procedures will be accomplished. ${ }^{2}$ Therefore, preclinical simulations should approach clinical reality in every way possible and should be designed to facilitate optimal assessment. ${ }^{3-6}$ Preclinical dental training using denti- 
form teeth that have artificial enamel and dentin with simulated caries may enhance students' skills later when they are managing patients with clinical caries. The use of simulated caries may allow formative and summative feedback that is more clinically relevant. Dentiform teeth with simulated caries (DTSC) are frequently used in preclinical operative dentistry courses, as well as in dental boards and licensure examinations in Canada. ${ }^{7}$

The manufacturing process of DTSC allows for designing the depth and width of simulated caries to create various learning experiences. DTSC may help students form awareness of the location of caries, its progression, and the interrelationships between its removal and the resultant shape of the cavity preparation. Instructor knowledge of the exact location and amount of the caries enables identification of the size and shape of the completed preparation. The predicted size and shape of the preparation allows for the development of clearly defined educational rubrics with associated criteria that differentiate levels of student performance. ${ }^{8}$ In addition, group problem-solving may be encouraged when multiple students are confronted with the same simulated disease state. ${ }^{9}$ The clinical educational value of this process depends on the anatomically correct localization of the caries and, once mass produced, the consistency of its placement from dentiform tooth to dentiform tooth.

Prototypes of DTSC, such as the one evaluated in this study, are provided to dental educators with a removable enamel shell. This shell facilitates creating dentin cavitation relative to adjacent proximal contacts and/or occlusal anatomy (Figure 1, panel a). The cavitation-containing dentin prototype is then mass produced in yellow-colored plastic so as to simulate dentin. Simulated caries have physical properties that mimic carious dentin in texture, and color (brown) is then placed by hand in the cavitation that was created in the dentin portion of the dentiform tooth. The enamel shell-like portion of the DTSC is cemented over the dentin with cement. There are no caries in the artificial enamel, which requires that faculty and students approximate where the enamel caries would form and estimate the level of enamel cavitation that would be clinically present. The DTSC are then mass-produced and commercially available for educational purposes.

First-year dental students (DDS1) at UNC take a series of summative practical examinations during their preclinical operative dentistry courses. The students participate in eight formative laboratory training sessions that are supplemented with didactic information, before they take their first summative practical examination (Practical 1), which consists of a two-surface MO mandibular preparation and Class II restoration with composite resin. The students then participate in another eight formative laboratory sessions before the second summative practical examination (Practical 2), which consists of a threesurface MOD maxillary preparation and Class II restoration with amalgam. The laboratory sessions and practical examinations utilize educational rubrics with specific criteria that define levels of performance for each dimension of the preparations and restorations. The removal of simulated caries in the DTSC,

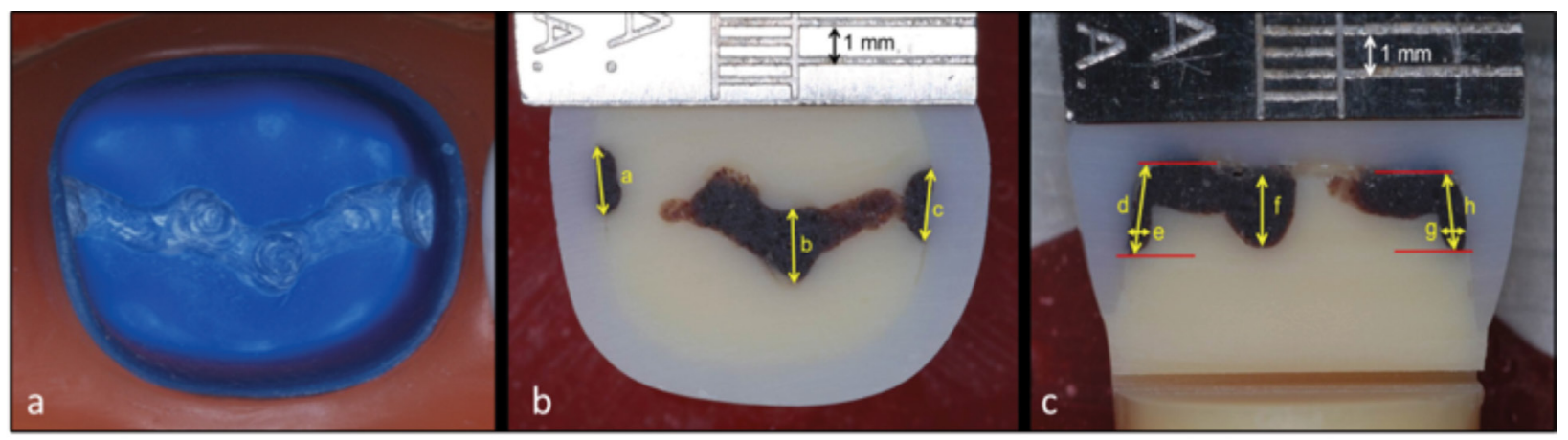

Figure 1. Blue dentin prototype (panel a), simulated caries width (panel b), and simulated caries depth (panel c)

Note: Panel a shows blue dentin prototype, with enamel removed, showing the strategically designed dentin cavitation. Panel b shows simulated caries width measured in the mesio-facio-lingual (a), occluso-facio-lingual (b), and disto-facio-lingual (c) regions of the horizontal sections. Panel c shows simulated caries depth measured in the mesio-gingival (d), mesio-axial (e), occluso-pulpal (f), disto-axial (g), and disto-gingival $(\mathrm{h})$ regions of the sagittal sections. 
when done correctly, will result in a preparation that meets course criteria. After additional didactic and laboratory training, students are required to complete two additional summative practical examinations that evaluate the development of other skill sets before completion of the preclinical course in operative dentistry.

Student experience in use of the DTSC in the preclinical simulation laboratory increased suspicion that there was caries variation among the DTSC as evidenced by large variation in the shape of the preparations that resulted after the simulated caries had been removed. Prior to our study, there were no published investigations relative to levels of caries variation among DTSC, so the level of caries variability among DTSC has been unknown. Excessive variation may result in faculty evaluation of student performance that fails to accurately reflect a correctly performed preparation and that negatively impacts summative outcomes. Knowing the prevalence and degree of variability among DTSC may help guide instructors and students relative to their preclinical operative dentistry experience. It may also raise awareness and inform manufacturers about manufacturing practices that reduce such variability.

The aim of this study was to assess variations in caries levels in one example of DTSC used as part of preclinical training in operative dentistry at UNC and to compare three years of DDS1 levels of practical performance using DTSC with three years of DDS1 levels of practical performance using dentiform teeth without simulated caries. The null hypothesis was that there was no difference in the level of caries extension among dentiform teeth with simulated caries.

\section{Materials and Methods}

This study (IRB \#14-3115) was reviewed by the UNC Office of Human Research Ethics and was exempted from further review according to the regulatory category cited under 45 CFR 46.101(b). For the study, 80 commercially produced mandibular right first molar DTSC (\#A27A-46U, Kilgore International, Inc., Coldwater, MI, USA) with mesio-occluso-distal caries were sectioned in coronal $(n=40)$ and sagittal $(n=40)$ planes where a pilot study had determined the caries depth/width was greatest. Custom acrylic jigs were fabricated to allow reproducible sections of DTSC, using a diamond impregnated slow-speed saw (Isomet 1000, Buehler Corp., Lake Bluff, IL, USA) at 375 RPM with water cooling at $25^{\circ} \mathrm{C}$. Standardized digital images, which incorporated a millimeter endodontic ruler for later calibration purposes (Union Broach, Moyco, York, PA, USA), were obtained using a DSLR camera (Nikon D60/Sigma 105 mm 1:2.8 Macro Lens, Lester Dine Inc., Palm Beach Gardens, FL, USA).

Each DTSC site was defined by the sum of the size (width or depth) of the caries plus the size of any caries that extended beyond the cavitation in each specimen measured to the nearest $0.01 \mathrm{~mm}$ using image-processing software (Image J $1.45 \mathrm{~s}$, National Institutes of Health, Bethesda, MD, USA) and reported to the nearest $0.1 \mathrm{~mm}$. For each site, the amount of caries overextension was calculated as the DTSC value minus the size of the caries that was limited to the size of the cavitation. Overextension that was $>0.5 \mathrm{~mm}$ was considered excessive. The mesio-facio-lingual (MFL), occluso-facio-lingual (OFL), and disto-facio-lingual (DFL) caries widths were measured in the coronal sections in the areas indicated in Figure 1, panel b. The mesio-gingival (MG), mesio-axial (MA), occluso-pulpal (OP), distoaxial (DA), and disto-gingival (DG) caries depths were measured in the sagittal sections in the areas indicated in Figure 1, panel c.

DDS1 performance levels on the preparation component of Practicals 1 and 2 were collected for six consecutive years. DTSC were being used in the preclinical operative dentistry course during years 1 , 2 , and 3. Dentiform teeth without simulated caries were used in the course for years 4,5 , and 6 . The outcome variable was defined as the performance level on the preparation aspect of Practicals 1 and 2 accomplished each year. The performance level was based on a scale of 1-100 points; 70 points was the minimum performance level for successful completion of the practical examinations. Data for all students in the designated years were included; each year had a class size of approximately 80 students.

The course was directed by one full-time faculty member (LWB) in the UNC Department of Operative Dentistry for the six years. The course design and core didactic content, with the exception of exclusion of the DTSC during the second three years, remained the same over the six-year period of data collection. Three of the four primary full-time faculty members remained the same over the six years of the study. Additionally, three graduate students enrolled in the Master's of Operative Dentistry program and three teaching assistants were utilized during the laboratory phase of the course. These personnel were different each year. Calibration of 
all faculty members, graduate students, and teaching assistants was conducted through yearly explanation and demonstration of teaching rubrics that detailed each dimension, along with definitions of dimension performance levels associated with the preparation and restoration of dentiform teeth (Table 1). Caries removal dimensions remained a part of the teaching rubrics even though simulated caries was no longer

Table 1. Rubric used to assess levels of performance for each dimension of mesio-occluso-distal preparation for amalgam

\begin{tabular}{|c|c|c|c|c|c|c|c|c|}
\hline \multirow[b]{2}{*}{ Initial Preparation } & \multicolumn{2}{|c|}{ Ideal } & \multicolumn{2}{|c|}{ Acceptable } & \multicolumn{2}{|c|}{ Requires Correction } & \multicolumn{2}{|c|}{ Unacceptable } \\
\hline & Student & Faculty & Student & Faculty & Student & Faculty & Student & Faculty \\
\hline Axis & \multicolumn{2}{|c|}{$\begin{array}{l}\text { I } \quad \text { I } \\
\text { parallel to crown } \\
\text { long axis }\end{array}$} & \multicolumn{2}{|c|}{$\begin{array}{cc}\text { A } & \text { A } \\
\text { minor axis discrepancy }\end{array}$} & & & \multicolumn{2}{|c|}{$\underset{\text { grossly off axis }}{U}$} \\
\hline Pulpal wall & \multicolumn{2}{|c|}{$\begin{array}{l}\leq 0.5 \mathrm{~mm} \text { internal to DEJ } \\
\text { (1.5-2.0 } \mathrm{mm} \text { total depth) }\end{array}$} & \multicolumn{2}{|c|}{$\begin{array}{c}\text { A } \quad A \\
\leq 1.0 \mathrm{~mm} \text { internal to DEJ } \\
(2.5-3.0 \mathrm{~mm} \text { total depth })\end{array}$} & \multicolumn{2}{|c|}{$\begin{array}{c}\text { C } \quad \text { C } \\
\text { enamel present on } \\
\text { pulpal wall } \\
(<1.5 \mathrm{~mm} \text { total depth })\end{array}$} & \multicolumn{2}{|c|}{$\begin{array}{c}\mathrm{U} \quad U \\
\geq 1.5 \mathrm{~mm} \text { internal to DEJ } \\
(\geq 3.5 \mathrm{~mm} \text { total depth })\end{array}$} \\
\hline Axial wall & \multicolumn{2}{|c|}{$\begin{array}{l}\quad \mathrm{I} \quad \mathrm{I} \\
\leq 0.5 \mathrm{~mm} \text { internal to DEJ } \\
\text { (1.0-1.5 mm total depth) }\end{array}$} & \multicolumn{2}{|c|}{$\begin{array}{c}\text { A A } \quad A \\
\leq 1.0 \mathrm{~mm} \text { internal to DEJ } \\
(2.0-2.5 \mathrm{~mm} \text { total depth) }\end{array}$} & \multicolumn{2}{|c|}{$\begin{array}{c}\mathrm{C} \quad \mathrm{C} \\
\text { enamel present on } \\
\text { axial wall } \\
\text { (<1.0 mm total depth) }\end{array}$} & \multicolumn{2}{|c|}{$\begin{array}{c}\quad \underset{\mathrm{mm} \text { internal to DEJ }}{\mathrm{U}} \\
(\geq 3.0 \mathrm{~mm} \text { total depth })\end{array}$} \\
\hline DEJ caries & I com & plete & & & \multicolumn{2}{|c|}{$\begin{array}{lr}\text { C } \quad C \\
\text { incomplete }\end{array}$} & & \\
\hline $\begin{array}{l}\text { Isthmus } \\
\text { (F/L extension) }\end{array}$ & \multicolumn{2}{|c|}{$\stackrel{\text { I }}{1.0-1.5 \mathrm{~mm} \text { wide }}$} & \multicolumn{2}{|c|}{$\begin{array}{cc}\text { A } & \text { A } \\
2.0-2.5 & \text { mm wide }\end{array}$} & $\begin{array}{c}\mathrm{C} \\
<1.0 \mathrm{~m}\end{array}$ & nide & \multicolumn{2}{|c|}{$\underset{\geq 3.0 \quad \mathrm{~mm} \text { wide }}{U}$} \\
\hline Primary retention & \multicolumn{2}{|c|}{$\begin{array}{l}\text { I } \\
\text { convergent }\end{array}$} & \multicolumn{2}{|c|}{$\mathrm{A}_{\text {parallel }}{ }^{\mathrm{A}}$} & $\begin{array}{c}\mathrm{C} \\
\text { excessive }\end{array}$ & $\begin{array}{c}\mathrm{C} \\
\text { nvergence }\end{array}$ & \multicolumn{2}{|c|}{$U_{\text {divergent }}^{U}$} \\
\hline Proximal clearance & \multicolumn{2}{|c|}{ 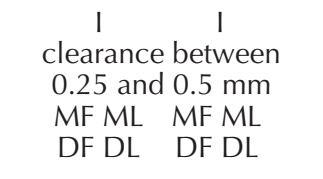 } & \multicolumn{2}{|c|}{$\begin{array}{c}\text { A } \quad \text { A } \\
\text { clearance } \\
>0.5 \text { and } \leq 0.75 \mathrm{~mm}\end{array}$} & \multicolumn{2}{|c|}{$\begin{array}{c}\mathrm{C} \quad \mathrm{C} \\
\text { inadequate clearance } \\
<0.25 \mathrm{~mm}\end{array}$} & $\begin{array}{c}U \\
\text { clearance }\end{array}$ & $\underset{\mathrm{U}}{\mathrm{U}}$ \\
\hline \multirow[t]{2}{*}{ Gingival clearance } & \multicolumn{2}{|c|}{$\begin{array}{c}\text { I } \\
\text { clearance between } \\
0.25 \text { and } 0.5 \mathrm{~mm}\end{array}$} & \multicolumn{2}{|c|}{$\begin{array}{c}\mathrm{A} \quad \mathrm{A} \\
\text { clearance } \\
>0.5 \text { and } \leq 0.75 \mathrm{~mm}\end{array}$} & \multicolumn{2}{|c|}{$\begin{array}{c}\mathrm{C} \quad \mathrm{C} \\
\text { inadequate clearance } \\
<0.25 \mathrm{~mm}\end{array}$} & \multicolumn{2}{|c|}{$\begin{array}{l}\text { U } \\
\text { clearance } \\
>0.75 \mathrm{~mm}\end{array}$} \\
\hline & $\begin{array}{l}\text { MG } \\
\text { DG }\end{array}$ & $\begin{array}{l}\text { MG } \\
\text { DG }\end{array}$ & $\begin{array}{l}\text { MG } \\
\text { DG }\end{array}$ & $\begin{array}{l}\text { MG } \\
\text { DG }\end{array}$ & $\begin{array}{l}\text { MG } \\
\text { DG }\end{array}$ & $\begin{array}{l}\text { MG } \\
\text { DG }\end{array}$ & $\begin{array}{l}\text { MG } \\
\text { DG }\end{array}$ & $\begin{array}{l}\text { MG } \\
\text { DG }\end{array}$ \\
\hline
\end{tabular}

Final Preparation

\begin{tabular}{|c|c|c|}
\hline Internal caries removal & $\begin{array}{c}\text { I } \\
\text { complete/ } \\
\text { conservative }\end{array}$ & $\begin{array}{c}\mathrm{A} \\
\text { Complete/ } \\
\text { non-conservativ }\end{array}$ \\
\hline Wall surfaces & I smooth & $A \underset{\text { rough }}{A}$ \\
\hline Wall transitions & $\stackrel{\text { I }}{\text { gentle transitions }}$ & \\
\hline
\end{tabular}

Cavosurface margins

I
enamel supported

Debridement

clean

Adjacent tooth

$$
\text { I no damage }
$$

C incomplete
C

U U

excessive

essive roughness

C C abrupt transitions
U U enamel unsupported margins $>100^{\circ}$
C debris
C $\mathrm{C}$ damage-recontour

$\underset{\text { damage-restore }}{U}$

Note: Assessment forms are divided into Initial Preparation and Final Preparation to provide for in-process feedback. 
present in the second three years of the study. This was to maintain integrity of the logical progression of thought relative to the goals of cavity preparation. DDS1 were required to accomplish a self-assessment prior to the faculty assessment during laboratory practices and practicals. Examples of ideal preparations and restorations, utilized throughout the course, were provided to faculty members during summative practical assessments as standards for ideal performance. Only full-time faculty and graduate students, who were blinded to student identity, were involved in scoring each of the practical assessments.

Descriptive statistics were used to assess the size of the caries in the sectioned DTSC without overextension as well as the size of the caries in those samples with overextensions that were $>0.5 \mathrm{~mm}$. Statistical analysis was used to assess whether practical performance level outcomes were significantly affected by use of DTSC. A paired dependent samples t-test compared the performance levels on Practicals 1 and 2 from six years of DDS1 performance (three years using DTSC and three years not using DTSC). The level of statistical significance was set at $p<0.05$.

\section{Results}

A manufacturing defect was found during the caries measurement process in the majority of the DTSC that resulted in caries overextension at the DEJ. The coronal sections without overextensions had a maximum of $0.3 \mathrm{~mm}$ caries variation among the regions evaluated; $70 \%$ had manufacturing defects that resulted in overextension at the DEJ. Of those with overextensions, $92.6 \%$ had MFL and $96.6 \%$ had DFL overextensions that were $>0.5 \mathrm{~mm}$, ranging from 1.5 to $4.5 \mathrm{~mm}$. The sagittal sections without overextensions had a maximum of $0.17 \mathrm{~mm}$ caries variation among the regions evaluated. Overextensions were found in $41.3 \%$. Of those that had overextensions, $81.3 \%$ had MG and $82.4 \%$ had DG overextensions that were $>0.5 \mathrm{~mm}$, ranging from 1.9 to $3.0 \mathrm{~mm}$.

The students' performance on the two practical exams is shown in Table 2. There was a significant decrease in the average level of performance on Practical 1 when the use of DTSC was compared to the average level of performance using dentiform teeth without simulated caries $(\mathrm{p}<0.0001)$. The DDS1 using DTSC had a mean performance level of 78.8, whereas the DDS1 who used dentiform teeth without simulated caries had a mean performance level of 87.6. There was no significant difference between the group using simulated caries (mean performance level=84.85) versus the group that did not use simulated caries (mean performance level $=85.74$ ) on Practical $2(\mathrm{p}=0.2189)$ (Figure 2).

\section{Discussion}

The clinical benefits of conserving healthy tooth structure support teaching operative methods that make possible the removal of caries without excessive removal of adjacent sound structure. DTSC simulate the spread of caries at the DEJ as well as pulpal (axial) caries progression. Teaching rubrics

\begin{tabular}{|c|c|c|c|c|c|c|}
\hline Year & Exam & $\mathrm{N}$ & Mean & Std. Dev. & Minimum & Maximum \\
\hline 1 & $\begin{array}{l}\text { Practical } 1 \\
\text { Practical } 2\end{array}$ & $\begin{array}{l}78 \\
78\end{array}$ & $\begin{array}{l}75.1 \\
89.0\end{array}$ & $\begin{array}{l}8.5 \\
8.6\end{array}$ & $\begin{array}{l}61.0 \\
67.0\end{array}$ & $\begin{array}{l}100.0 \\
100.0\end{array}$ \\
\hline 2 & $\begin{array}{l}\text { Practical } 1 \\
\text { Practical } 2\end{array}$ & $\begin{array}{l}81 \\
81\end{array}$ & $\begin{array}{l}79.7 \\
82.4\end{array}$ & $\begin{array}{l}7.7 \\
6.4\end{array}$ & $\begin{array}{l}70.0 \\
70.0\end{array}$ & $\begin{array}{l}97.0 \\
98.0\end{array}$ \\
\hline 3 & $\begin{array}{l}\text { Practical } 1 \\
\text { Practical } 2\end{array}$ & $\begin{array}{l}82 \\
82\end{array}$ & $\begin{array}{l}81.5 \\
83.4\end{array}$ & $\begin{array}{l}7.2 \\
9.6\end{array}$ & $\begin{array}{l}74.0 \\
72.0\end{array}$ & $\begin{array}{c}98.0 \\
100.0\end{array}$ \\
\hline 4 & $\begin{array}{l}\text { Practical } 1 \\
\text { Practical } 2\end{array}$ & $\begin{array}{l}83 \\
83\end{array}$ & $\begin{array}{l}89.7 \\
84.4\end{array}$ & $\begin{array}{c}10.3 \\
7.1\end{array}$ & $\begin{array}{l}53.0 \\
58.0\end{array}$ & $\begin{array}{c}100.0 \\
96.0\end{array}$ \\
\hline 5 & $\begin{array}{l}\text { Practical } 1 \\
\text { Practical } 2\end{array}$ & $\begin{array}{l}81 \\
81\end{array}$ & $\begin{array}{l}89.4 \\
87.8\end{array}$ & $\begin{array}{l}6.2 \\
7.4\end{array}$ & $\begin{array}{l}71.0 \\
66.0\end{array}$ & $\begin{array}{l}100.0 \\
100.0\end{array}$ \\
\hline 6 & $\begin{array}{l}\text { Practical } 1 \\
\text { Practical } 2\end{array}$ & $\begin{array}{l}80 \\
80\end{array}$ & $\begin{array}{l}83.6 \\
85.1\end{array}$ & $\begin{array}{l}8.7 \\
6.1\end{array}$ & $\begin{array}{l}53.0 \\
70.0\end{array}$ & $\begin{array}{c}100.0 \\
97.0\end{array}$ \\
\hline
\end{tabular}

Note: Scores are based on a 1-100 range, with a score of 70 required for passing. DTSC were used in years 1,2 , and 3 . Dentiform teeth without simulated caries were used in years 4, 5, and 6 . 

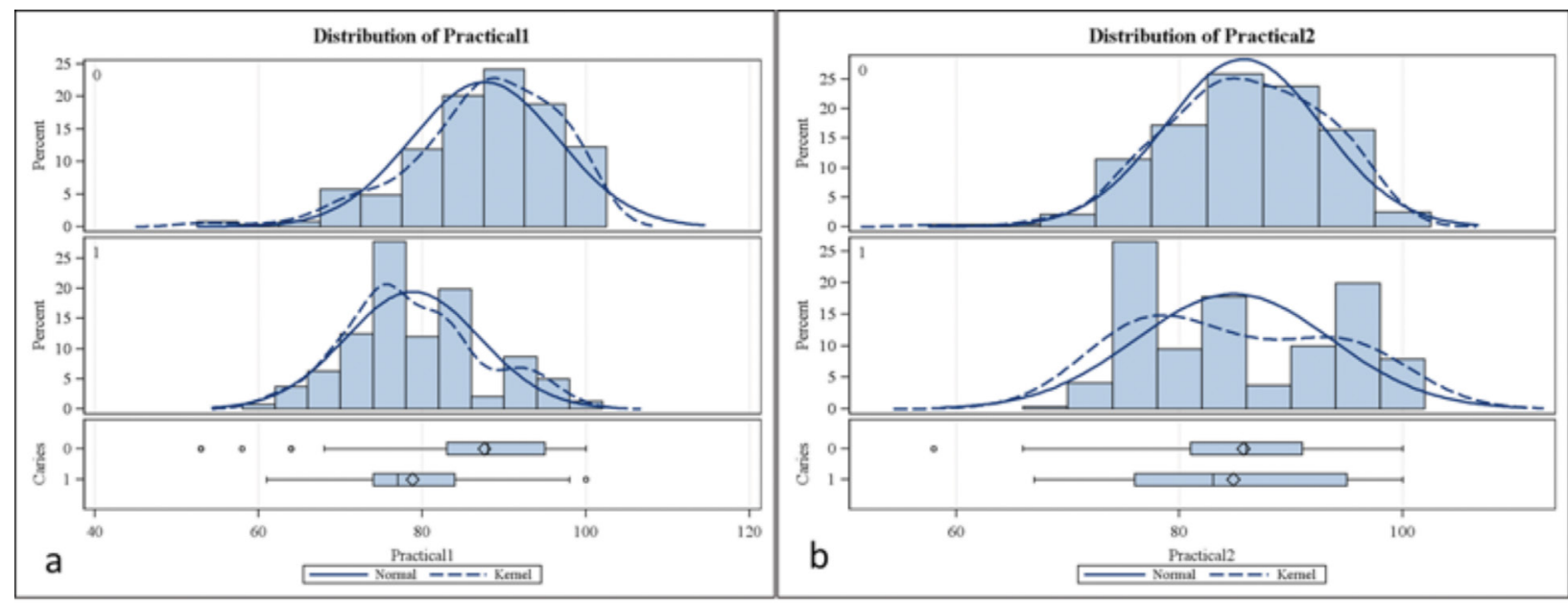

Figure 2. Average DDS1 performance level on Practical 1 (panel a) and average DDS1 performance level on Practical 2 (panel b)

Note: Panel a shows average DDS1 performance level (as a percentage) distribution of Practical 1 when DTSC were used ( $1=$ caries, $0=$ no caries simulation). There was a statistically significant decrease in student performance level on Practical 1 when DTSC were used during the course $(p<0.0001)$. Panel b shows average DDS1 performance level on Practical 2 . There was no statistically significant diffence in student performance level on Practical 2 when DTSC were used during the course $(p=0.2189)$. $X$ axis=level of practical performance. $Y$ axis=percentage of students at various performance levels.

associated with DTSC are designed such that each student's preparation can be assessed based on conservative caries removal that results in a preparation of specific measurable width, depth, and clearance from adjacent proximal surfaces.

The criteria for an acceptable overall occlusal and proximal preparation extension require complete removal of the caries at the DEJ and at the internal pulpal/axial walls. Incomplete removal of the DEJ caries is deemed unacceptable. ${ }^{1}$ The DTSC evaluated in this study utilized a strategic design of the caries position such that complete caries removal would allow for small, conservative preparations that result in minimal clearance $(\leq 0.5 \mathrm{~mm})$ with the proximal surfaces of adjacent dentiform teeth. Preparations such as these would be assessed as ideal and represent the development of appropriate control of the highspeed handpiece. Initially, students are instructed to initiate the preparation into the tooth until the carious DEJ is reached. At the depth of the DEJ, students then extend their preparation facially, lingually, and gingivally until no more caries is detected at the DEJ. In this way, caries removal determines the position of the proximal and gingival walls and results in clearances with proximal surface of the adjacent tooth.

It has been recognized that, when it comes to the evaluation of student preclinical performance of operative procedures, there is a need for clinically accurate simulations that can be objectively assessed. ${ }^{10}$ If a dentiform tooth with simulated caries has a manufacturing defect consisting of excessive extension of caries at the DEJ, it will result in overall completed preparation dimensions (as measured by proximal and/or gingival clearance) that are assessed as greater than expected. The student's performance on the caries removal would be deemed less than ideal or even unacceptable even though the student correctly implemented the procedure in an ideal fashion. Objectivity in the assessment process would then have been lost (Figure 3, Figure 4, Figure 5). ${ }^{3}$ The presence of excessive axial or pulpal caries has the same potential for inaccurate assessment of the student's performance. It is important to note that sectioning in the facial plane was not used in this study, and the level of caries variation associated with the occlusal DEJ is unknown. Overextensions in this region have the potential to result in faciolingual overextension and excessive width of the occlusal isthmus.

It is reasonable to find minor caries variation among a sample of DTSC being used for a particular preclinical exercise. The question that arises is this: What level of variation would result in completed preparations that, even though correctly accom- 


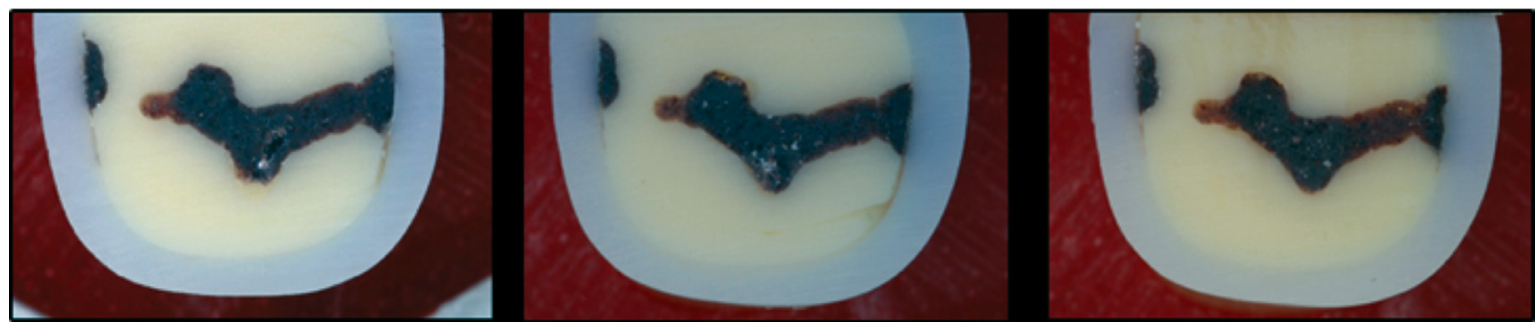

Figure 3. Examples of coronal sections with manufacturing defects that resulted in caries overextension at the DEJs

Note: The manufacture of all DTSC should be equivalent.

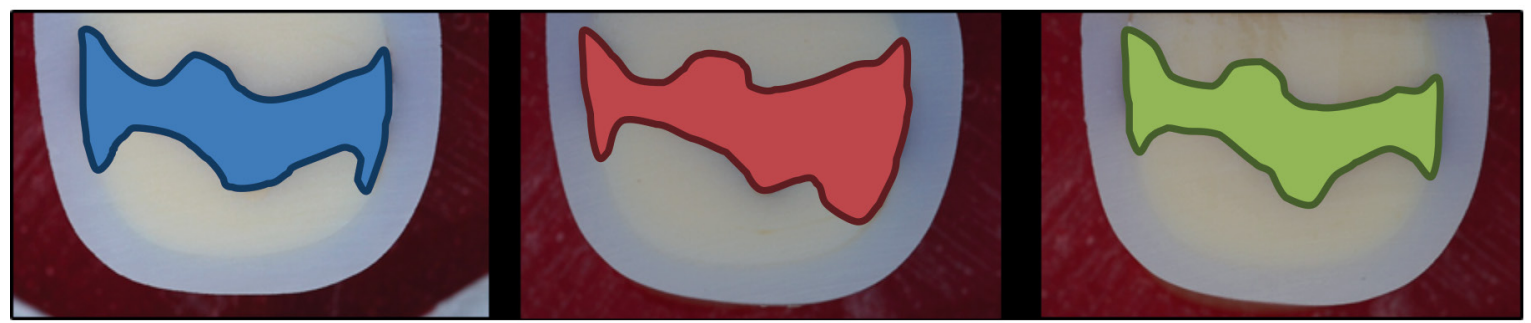

Figure 4. Coronal sections in Figure 3 with anticipated cavity preparation outlines, which would result from caries removal accomplished in an appropriate manner, shaded in three colors

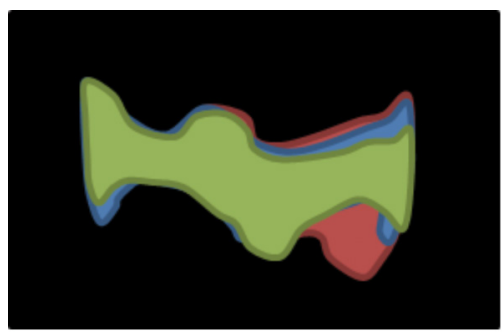

Figure 5. Cavity preparation outlines from Figure 4 superimposed over each other

Note: Green would be assessed as an ideal cavity preparation, blue an acceptable cavity preparation, and red an unacceptable cavity preparation.

plished, would still be assessed as less than ideal because of resultant increased preparation width and depth? When one is seeking to identify a maximum level of variation in DTSC that will not adversely impact assessment of student performance, it is important to note that there may be a lower limit to the ability of dental faculty members and students to accurately and consistently estimate width or depth measurements.

One study of 163 dental students and 20 experienced dentists found that $50 \%$ or less of the study participants were able to estimate clinically relevant lengths (range 0.5 to $5.0 \mathrm{~mm}$ ) to within $0.5 \mathrm{~mm}$ of the actual length. ${ }^{11}$ Increased clinical experience improved the participants' ability to estimate length, but even the most experienced dentists in that study were able to estimate the length to within $0.5 \mathrm{~mm}$ only $50 \%$ of the time. This finding suggests that distances smaller than $0.5 \mathrm{~mm}$ may be below the lower threshold of consistent estimation. Preclinical dental courses utilize various measurement devices (such as thickness gauges, probes, and magnification) to increase levels of measurement accuracy. The UNC criteria for posterior proximo-occlusal preparations require that the final clearance between the proximal and gingival cavosurface margins and the adjacent teeth be $\leq 0.5 \mathrm{~mm} .{ }^{1}$ The design of the position of the simulated caries in the dentiform teeth evaluated in our study would leave proximal and gingival clearances in the ideal range when prepared correctly. This requires a defect-free manufacturing process. 
Overextensions that extend $>0.5 \mathrm{~mm}$ will result in preparations that are assessed as less than ideal even in the circumstance in which students correctly perform the procedure. Therefore, we set the cut-off for acceptable caries variation in the DTSC at $0.5 \mathrm{~mm}$.

The amount of caries variation among DTSC without overextensions was well below $0.5 \mathrm{~mm}$. However, a majority of the DTSC evaluated in this study had overextensions in one or more regions of the tooth. Regions where excessive caries variation was most likely to have a negative influence on the assessment of student performance were facial, lingual, and gingival DEJ areas on the proximal surfaces. Preparation of the proximal surfaces is already difficult because of access limitations, and the potential for manufacturing defect overextensions in this area further threatens objective assessment of preparation implementation. If DTSC could be consistently manufactured without overextensions, then formative and summative assessments would have higher educational value. Other DTSC representing anterior/posterior and maxillary/mandibular areas of the dentition are commercially available but with unknown levels of caries variability.

DDS1 learn and develop hand-eye coordination at different rates. Early in the preclinical operative dentistry course, the DDS1 are novice learners and, as such, require careful detailed instruction with timely assessment along with plenty of repetition and practice. ${ }^{12}$ In general, it has been observed that, by the end of preclinical operative dentistry courses, most students develop the skill set necessary for safe transition into clinical care. ${ }^{13}$ However, the presence of an unknown complexity, such as variable levels of caries in the DTSC, may be more difficult for DDS1 to deal with early in the preclinical course than it would be as they continue to mature in their mastery of operative dentistry concepts and associated motor skills. This immaturity may partly explain the statistically significant difference found in our study between the students' Practical 1 performance when using DTSC and when dentiform teeth without simulated caries were used as well as why this difference did not continue later in the course (as assessed by the comparison of performance on Practical 2 with and without DTSC). The imperfections of the simulation process, as in the case of DTSC, present less of a challenge as DDS1 mature and begin to recognize and adjust their approach when manufacturing flaws are present. Surely this development of an artificial awareness and tendency to then ignore the DEJ defect is counterproductive in learning that enamel must be supported by dentin in the stress-bearing areas of the mouth, one of the basic principles of operative dentistry.

A limitation of our study is that the level of faculty calibration was unknown, and that raises concerns with regard to the consistency of faculty formative and summative assessments. Use of teaching rubrics with specific performance criteria and descriptions of levels of performance, combined with student self-assessment prior to faculty assessment, may help limit subjectivity. However, additional steps to provide for calibration among the examiners, with reliability testing, are warranted in future studies. Another limitation is that, since the study took place at only one dental school, its results may not be generalizable, although examining results over multiple years reduced the possibility that the findings were affected by distinctive conditions of one group of students.

\section{Conclusion}

Dentiform teeth with simulated caries may have manufacturing defects, so the aims of this study were to assess the likelihood of such defects in DTSC and their impact on student performance. The results showed that $70 \%$ of the coronal sectioned and $41 \%$ of the sagittal sectioned DTSC evaluated had caries overextensions. Of these, more than $80 \%$ were found to have excessive simulated caries variation in at least one region. Prediction of which dentiform teeth with simulated caries will have caries overextensions could not be determined in this study and may be impossible. The variation was found to have much greater impact on students' performance on the first practical exam than on the second. Students at the earliest stage of their preclinical development may be more likely to strictly adhere to key instruction principles in steps that require preparation extension along the DEJ and may fail to recognize the presence of a defect in the DTSC. This oversight may result in a tooth preparation that is deemed less than ideal and may increase the student's risk of receiving a negative summative assessment even though the preparation was accomplished correctly.

\section{Acknowledgments}

The study was funded by the University of North Carolina at Chapel Hill School of Dentistry Educational Research Grant \#3-13960. 


\section{REFERENCES}

1. Heymann HO, Swift EJ Jr, Ritter AV. Sturdevant's art and science of operative dentistry. $6^{\text {th }}$ ed. St. Louis: Elsevier Mosby, 2013.

2. Nunez DW, Taleghani M, Wathen WF, Abdellatif HMA. Typodont versus live patient: predicting dental students' clinical performance. J Dent Educ 2012;76(3):407-13.

3. Vanek HG. Objective evaluation of dental student technic products. J Dent Educ 1969;33(1):140-4.

4. Salvendy G, Hinton WM, Ferguson GW, Cunningham PR. Pilot study on criteria in cavity preparation: facts or artifacts? J Dent Educ 1973;37(11):27-31.

5. Mackenzie RS, Antonson DE, Weldy PL, et al. Analysis of disagreement in the evaluation of clinical products. $\mathrm{J}$ Dent Educ 1982;46(5):284-9.

6. Haj-Ali R, Feil P. Rater reliability: short- and long-term effects of calibration training. J Dent Educ 2006;70(4): 428-33.
7. National Dental Examining Board of Canada. Equivalency process assessment of clinical skills protocol. Ottawa: National Dental Examining Board of Canada, 2014.

8. O'Donnell JA, Oakley M, Haney S, et al. Rubrics 101: a primer for rubric development in dental education. J Dent Educ 2011;75(10):1163-75.

9. Satterthwaite JD, Grey NJ. Peer-group assessment of preclinical operative skills in restorative dentistry and comparison with experienced assessors. Eur J Dent Educ 2008;12:99-102.

10. Mossey PA, Newton JP, Stirrups DR. Scope of the OSCE in the assessment of clinical skills in dentistry. Br Dent $\mathrm{J}$ 2001;190:323-6.

11. Dimitrijevic T, Khaler B, Evans G, et al. Depth and distance perception of dentists and dental students. Oper Dent 2011;36:446-77.

12. Hauser AM, Bowen DM. Primer on preclinical instruction and evaluation. J Dent Educ 2009;73(3):390-8.

13. Gansky SA, Pritchard H, Kahl E, et al. Reliability and validity of a manual dexterity test to predict preclinical grades. J Dent Educ 2004;68(9):985-94. 